\title{
Damage Analysis Of Sea-Crossing Bridge Main Pier Pile Foundations Under Wave Loading By Scouring Different Situation
}

\author{
Zhang Xuefeng ${ }^{1,2, a}$, Li Qingning ${ }^{2, b}, M a$ Ye $^{1, c}$, Zheng Ruiping ${ }^{3, d}$ \\ ${ }^{1}$ Bridge Research Center,Research Institute of Highway Ministry of Transport,china; \\ ${ }^{2}$ Civil engineering College, Xi'an University of Architecture and Technology, ,china; \\ ${ }^{3}$ Hangzhou Highway Bridge Science Technology Co., Ltd. ,china; \\ a13185011966@163.com, ${ }^{\mathrm{b}}$ qn.1419@163.com, ${ }^{\mathrm{c} y y . m a @ r i o h . c n},{ }^{\mathrm{d}}$ 371028530@qq.com
}

\begin{abstract}
Keywords: Sea-crossing bridge; Main pier foundations; Scouring; Damage analysis;
Abstract. Since the Bridge is generally span, the main pier and more in the deep water area, combined with the harsh coastal or marine environments, heavy marine traffic must be many ways to strengthen security maintenance Bridge, the current damage identification and safety warning technology by the upper structure more attention to the role of Bridge often bear strong winds, big waves. Since the wind - waves - liquid coupling mutagenic effects, long-term effects, effects of fatigue and the effects of aging and deterioration of materials and other unfavorable factors, in order to grasp the Sea-Crossing Bridge Main Pier Pile Foundations work under wave loading by scouring different situation state and force deformation characteristics, the present analysis Theoretical analysis of wave loads by different scouring status under the numerical simulation method.
\end{abstract}

\section{Summary}

Since the Bridge is generally span, the main pier and more in the deep water area, combined with the harsh coastal or marine environments, heavy marine traffic must be many ways to strengthen security maintenance Bridge, the current damage identification and safety warning technology by the upper structure more concerned about the technology is relatively perfect, but the relative lack of structure and foundation for the lower part of the damage identification and safety early warning technology research. Due to the lower part of the structure and foundation are more affected by the marine environment and geological conditions, especially the main pier foundation, because of the geological environment by Watermark Haute point and their own characteristics and bearing, and the upper structure vary greatly, the corresponding damage identification and analysis of damage evaluation techniques are quite different and the upper structure, and therefore requires special study.

Bridge often bear the role of strong winds, big waves. Since the wind - waves - liquid coupling effect of mutations affecting the long-term effects, effects of fatigue and aging and deterioration of materials and other unfavorable factors, the large bridge substructure will inevitably produce damage accumulation, resistance and attenuation function degradation, extreme the case of easily lead to catastrophic incidents.Okeil and Cai an extensive survey of the US Hurricane Katrina's destruction of coastal bridge, found the bridge collapse was mainly due to the impact of waves and currents under the combined effect of horizontal loads over a bridge structure connecting the upper and lower parts of the ability. Padgett and Arnold investigated the destruction of the reasons the United States after Hurricane Katrina bridges that wind, waves, flow, etc. are the main cause of damage to the bridge, including the strength of the impact of storms, the impact of drifting objects, wind and flooding caused destruction.

\section{Damage model of concrete structures}

To master the Sea-Crossing Bridge Main Pier Pile Foundations under different working conditions scouring situation under stress wave loading and deformation characteristics by the research analysis of the injury indicators were in the wave action of the stress analysis by numerical simulation method. 
In this study, Bridge Main Pier Foundation injury model using specifications recommended stress-strain curve derived uniaxial damage evolution equation [. Using different assumptions damage model evolution equations different equations. Not in the actual project ready-made concrete stress - strain curve, usually through the corresponding tensile strength, compressive strength and modulus of elasticity to approximate description. When the limit is reached before the stress, and it is assumed that the stress - strain curve is a straight line, this stage there is no damage, stress after reaching the ultimate stress in accordance with the specification given in - strain curve, usually with an energy equivalence principle to derive concrete material ABAQUS Input data.

Concrete Members stress during uniaxial tensile - strain curve to determine:

$$
\text { While } x \geq 1 \quad y=\frac{x}{\alpha_{t}(x-1)^{1.7}+x}
$$

Similarly concrete under uniaxial tensile stress-strain curve equation are determined according to the following formula:

$$
\text { While } x \geq 1 \quad y=\frac{x}{\alpha_{d}(x-1)^{2}+x}
$$

Among them $\alpha_{t}=0.312 f_{t}^{2}, \alpha_{d}=0.157 f_{c}^{0.785}-0.905$ 。

Using the energy equivalence principle can be drawn:

Uniaxial tensile damage equation:

$$
\begin{array}{cc}
D=0 & x \leq 1 \\
D=1-\sqrt{\frac{1}{\left[\alpha_{t}(x-1)^{17}+x\right]}} & x>1
\end{array}
$$

Uniaxial compression damage equation:

$$
\begin{array}{cc}
D=0 & x \leq 1 \\
D=1-\sqrt{\frac{1}{\left[\alpha_{d}(x-1)^{2}+x\right]}} & x>1
\end{array}
$$

\section{Numerical Simulation Analysis and Modeling}

In this paper, the Hangzhou Bay Bridge engineering calculation examples using ABAQUS finite element software D13 Main Piers of Northern Waterway Bridge pile foundation analysis the damage modeling.

Project Overview

Hangzhou Bay Bridge 36 kilometers, the bridge across the Hangzhou Bay, the sea tide is strong, large tidal range, suspended sediment and bed particle size is consistent, seabed sediment deposition in the complex, resulting in the development and changes of seabed trench faster, become a bridge pier local scour the safe operation of the potential risks. North Channel Bridge of Hangzhou Bay Bridge, the bridge span by $230 m+448 m+230 m$ fan towers and double cable planes are arranged three-span continuous cable-stayed bridge, with a rubber bearing basin on the pylon, semi-floating system, the overall Bridge picture is in Fig.1. 


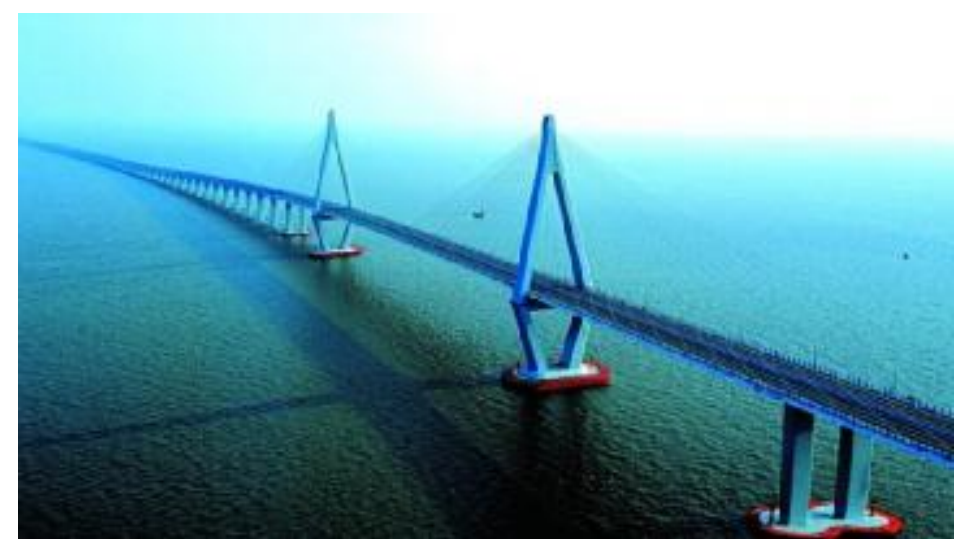

Fig.1 The hangzhou bay bridge

The use of large finite element software ABAQUS simulation simulation analysis

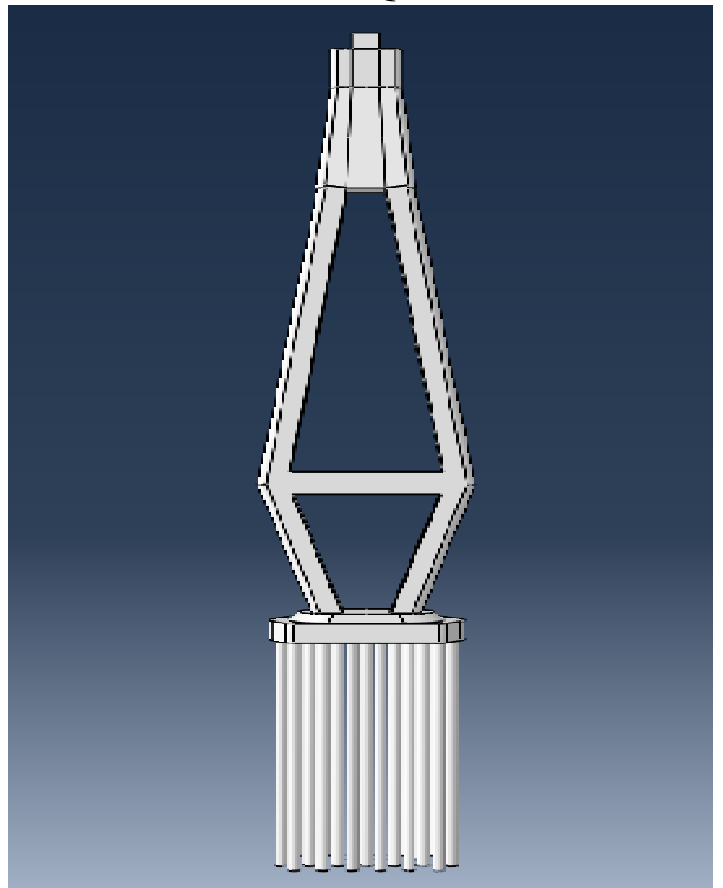

Fig.2 Hangzhou bay bridge D13 pier model

\section{Numerical simulation results}

Under each load condition, pier Damage condition is in tab.1. Typical conditions (erosion 40m) calculation of cloud shown in Fig.3 to Fig. 4.

Tab.1 Pier scouring case damage results

Condition number

Condition 1: scour 10m

Condition 2: scour 20m

Condition 3: scour 40m

Condition 4: scour 60m
Damage condition

Pylon beam cracking damage; pile foundation began cracking damage of reinforced not to yield.

Pylon beam cracking damage; pile foundation began cracking damage, did not yield steel, pier top horizontal displacement starts to increase.

Pylon beam cracking damage; pile foundation began cracking damage, did not yield steel, pier top horizontal displacement increases.

Pylon beam cracking damage; pile foundation began to crack damaged area increased steel began to yield pier top horizontal displacement continues to increase. 


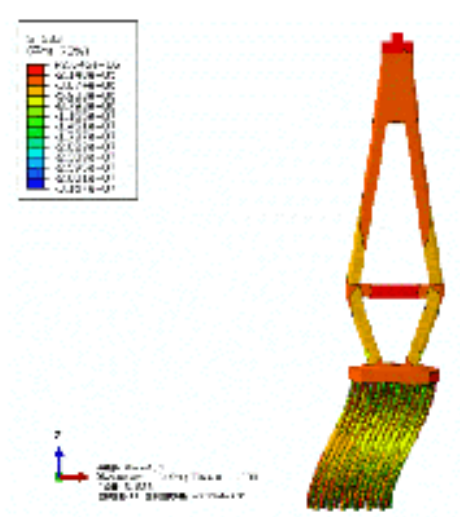

a)Pier concrete $S 33$

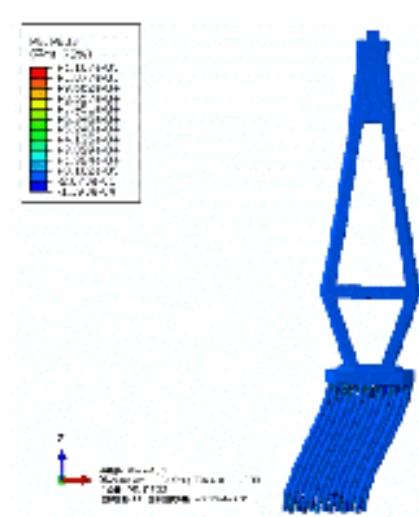

b)Pier concrete PE

\section{Fig. 3 Main Pier strain cloud}

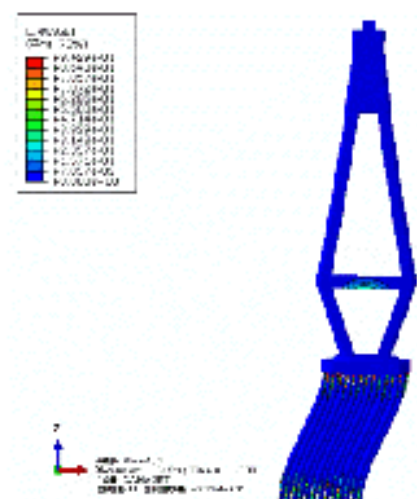

a)The whole idea

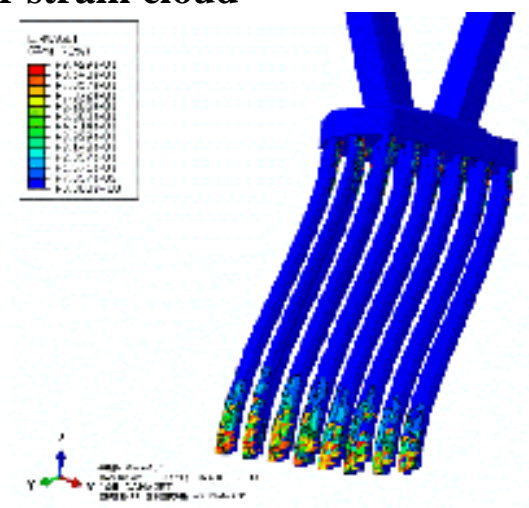

b)Partial view

Fig. 4 Main Pier DAMAGET cloud

\section{Conclusions}

(1)Main pier foundations scour depth of $20 \mathrm{~m}$ under state wave loading pier beams cracking damage, under the pile top and bottom partial cracking damage.

(2)Main pier foundations scour depth of $40 \mathrm{~m}$ under the state pier beam wave loads crack serious injury, the bottom of the pier, under the pile at the top and bottom partial cracking damage.

(3) Main pier foundations scour depth of $40 \mathrm{~m}$ under the state pier beam wave loads crack serious injury, the bottom of the pier, under the pile at the top and bottom partial damage cracking, steel yielding occurs.

(4)Sea-Crossing bridge main pier foundations of scouring depth different state by wave loads mainly for the pier top horizontal displacement continues to increase, leading to structural steel yielding accelerate the collapse destroying.

\section{References}

[1] Okeil A M,Cai.Warping stresses in curved box girder bridges:case study[J].Journal of Bridge Engineering,2008,9(5):487-496.

[2] Padgett A S, Arnold M M. Calibration of design code for buildings (ACI318) I : Statistical models for resistance[J]. ACI Structural Journal, 2009, 100(3): 377 -382.

[3] Feng Bohao, Zhang Lixiang, Li Guiqing. Summary of concrete damage [J] Kunming University of Science: Science \& Engineering, 2001, 26 (3): 21-30.

[4] Lou Zhiwen. Mechanics base damage [M]. Xi'an Jiaotong University Press, 1991.

[5] Liu Changchun, Lu and Xiang, Guan Ping.Viscoplastic damage constitutive model for concrete materials [J] Applied Mathematics and Mechanics, 2007, 28 (9): 1021-1027.

[6] Ding Faxing, Yu Zhiwu, Ou Jinping.Concrete under uniaxial stress damage constitutive model [J] by Chang'an University: Natural Science Edition, 2008, 28 (4): 70-73.

[7] Lv Zhongda.Key Technology Research and Implementation of the Hangzhou Bay Bridge [J] Civil Engineering Journal, 2006, 39 (6): 78-82. 